\title{
Perbandingan Tingkat Kecepatan Konvergensi dari Metode Newton Raphson dan Metode Secant Setelah Mengaplikasikan Metode Aiken's dalam Perhitungan Akar Pangkat Tiga
}

\author{
Elis Ratna Wulan, Sri Mulyati Sukarti, Diny Zulkarnaen \\ Jurusan Matematika Fakultas Sains dan Teknologi UIN Sunan Gunung Djati Bandung \\ Jln. A.H. Nasution No. 105 Cibiru Bandung 40614 \\ Email : elis_ratna_wulan@uinsgd.ac.id
}

\begin{abstract}
ABSTRAK
Persamaan nonlinier merupakan salah satu kajian dalam ilmu matematika. Pencarian akar dalam persamaan non linier yang rumit dapat diselesaikan dengan metode numerik. Banyak metode untuk menyelesaikan persamaan tersebut. Metode yang digunakan dalam penelitian ini adalah Metode NewtonRaphson, Metode Secant dan Metode Aitken's $\Delta^{2}$. Metode Newton-Raphson dan Metode Secant digunakan untuk menghitung tingkat konvergensi, sedangkan Metode Aitken's $\Delta^{2}$ digunakan untuk mempercepat konvergensi dari Metode Newton-Raphson dan Metode Secant. Dalam Metode Newton-Raphson memerlukan satu tebakan awal sedangkan dalam metode Secant memerlukan dua tebakan awal. Dalam menyelesaikan contoh pertama dengan menggunakan metode Newton-Raphson, pada saat iterasi ke-6 diperoleh nilai yaitu 1 dan ketika mengaplikasikannya dengan metode Aitken's $\Delta^{2}$ tingkat kecepatan konvergensi dapat diperoleh dengan nilai yang sama yaitu 1 hanya pada saat iterasi ke-5. Sedangkan dengan menggunakan metode Secant pada saat iterasi ke-2 telah diperoleh nilai yaitu 1 dan ketika mengaplikasikannya dengan metode Aitken's $\Delta^{2}$ tingkat kecepatan konvergensi dapat diperoleh dengan nilai yang sama yaitu 1 hanya pada saat iterasi ke-1. Untuk contoh ke dua dengan menggunakan metode Newton-Raphson, pada saat iterasi ke-5 diperoleh nilai yaitu 2,962489 dan ketika mengaplikasikannya dengan metode Aitken's $\Delta^{2}$ tingkat kecepatan konvergensi dapat diperoleh dengan nilai 2,96249 pada saat iterasi ke-4. Sedangkan dengan menggunakan metode Secant pada saat iterasi ke-5 telah diperoleh nilai yaitu 2,962490799 dan ketika mengaplikasikannya dengan metode Aitken's $\Delta^{2}$ tingkat kecepatan konvergensi dapat diperoleh dengan nilai 2,962501 pada saat iterasi ke-4.
\end{abstract}

Kata kunci: Metode Numerik, Persamaan Non Linear, Metode Newton, Metode Secant, Tingkat Konvergensi, Metode Aitken's $\Delta^{2}$.

\begin{abstract}
Non linear equation is one of the studies in mathematics. To find solution to the roots of complex non linear equations can be solved of numerical method. In this paper, the method used is the Newton-Raphson Method, Secant method and Aitken's $\Delta^{2}$. Newton-Raphson method and Secant method is used tocalculate the rate of convergence, while Aitken's $\Delta^{2}$ method used to accelerate the convergence of Newton-Raphson method and the Secant method. In Newton-Raphson method required an initial guess, while the Secant method required two initial guesses. To fine solution of an example of unity with the used Newto-Raphson method, when iteration 6 find the value is 1 and when applying Aitken's $\Delta^{2}$ method the accelerat of convergence can find the same value is 1 just when iteration 5. While used the Secant method of the when iteration 2 find the value is 1 and when applying Aitken's $\Delta^{2}$ method the accelerat of convergence can find the same value is 1 just when iteration 1. While for the second example with the used Newto-Raphson method, when iteration 5 he value is 2.962489 and when applying Aitken's method the accelerate of convergen can find 2.96249 when iteration 4. While the Secant method, when iteration 5 find the value is 2.962490799 and when applying Aitken's method the accelerate of convergen can find 2.962501 with iteration 4.
\end{abstract}

Keywords: Numerical Method, Non Linear Equations, Newton Method, Secant Method, Rate of Convergence, Aitken's $\Delta^{2}$ Method. 


\section{Pendahuluan}

Metode Newton Raphson adalah metode yang banyak digunakan dari semua formula penempatan akar. Jika tebakan awal dari akar adalah $x_{i}$, maka sebuah garis singgung dapat dibuat melalui titik $\left[x_{i}, f\left(x_{i}\right)\right]$. Titik dimana garis singgung ini memotong sumbu $x$. Metode Newton Raphson dapat diturunkan berdasarkan interpretasi geometrik. Sedangkan formula untuk metode Secant memerlukan dua taksiran awal $x$. Metode Newton Raphson dan metode Secant keduanya hampir serupa, dalam arti bahwa suatu taksiran akar diramalkan oleh ekstrapolasi sebuah garis singgung dari fungsi terhadap sumbu $x$ [1]. Tetapi metode Secant lebih menggunakan diferensi dari pada turunan untuk memakai kemiringan. Metode Aitken's $\Delta^{2}$ digunakan untuk mempercepat konvergensi metode Newton Raphson dan metode Secant dalam mendapatkan nilai akar sebenarnya.

\section{Metode Penelitian}

Metode penelitian yang digunakan berupa pendekatan teoritis atau studi literatur dari berbagai sumber yang berkaitan dengan solusi numerik. Pencarian akar menggunakan metode Newton Raphson dan metode Secant. Adapun bentuk fungsi yang dibahas yaitu $f(x)=x^{3}-c$.

\section{Hasil dan Pembahasan}

\subsection{Metode Newton Raphson}

Metode Newton Raphson dapat diturunkan berdasarkan interpretasi geometrik (sebuah metode alternatif yang didasarkan pada Deret Taylor). Seperti pada Gambar 1 turunan pertama pada $x_{i}$ adalah ekuivalen terhadap kemiringan (slope) [2]:

yang dapat diatur kembali menjadi :

$$
f^{\prime}\left(x_{i}\right)=\frac{f\left(x_{i}\right)-o}{x_{i}-x_{i}+1}
$$

yang dinamakan formula Newton-Raphson.

$$
x_{i}+1=x_{i}-\frac{f\left(x_{i}\right)}{f^{\prime}\left(x_{i}\right)}
$$

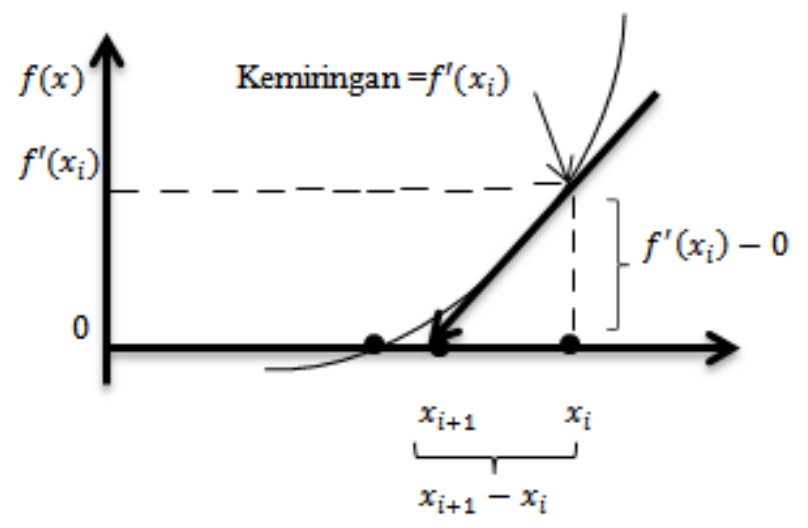

Gambar 1 Metode Newton Raphson [2]

Pada Gambar 1, fungsi $f(x)$ adalah kontinu. Garis singgung terhadap fungsi pada $x_{i}$ [yakni $f^{\prime}\left(x_{i}\right)$ ] diekstrapolasikan ke bawah terhadap sumbu x untuk memberikan sebuah taksiran akar pada $x_{i}+1$.

Di samping penurunan 36lternati, metode Newton Raphson biasanya dikembangkan dari perluasan Deret Taylor. Penurunan 36lternative ini berguna dalam memberikan pengertian terhadap laju konvergensi dari metode Newton Raphson. Perluasan dari Deret Taylor dapat dinyatakan sebagai [4]:

$$
f\left(x_{i+1}\right)=f\left(x_{i}\right)+f^{\prime}\left(x_{i}\right)\left(x_{i+1}-x_{i}\right)+\frac{f^{\prime \prime}(\varepsilon)}{2}\left(x_{i+1}-x_{i}\right)^{2}
$$


Di mana $\varepsilon$ terletak di sembarang tempat dalam interval $x_{i}$ hingga $x_{i+1}$. Sebuah versi aproksimasi diperoleh dengan memotong deret setelah suku turunan pertama:

$$
f\left(x_{i+1}\right) \approx f\left(x_{i}\right)+f^{\prime}\left(x_{i}\right)\left(x_{i+1}-x_{i}\right)
$$

Pada perpotongan dengan sumbu $x, f\left(x_{i+1}\right)$ akan sama dengan nol, atau

$$
0 \approx f\left(x_{i}\right)+f^{\prime}\left(x_{i}\right)\left(x_{i+1}-x_{i}\right)
$$

Dapat diselesaikan untuk:

$$
x_{i+1}=x_{i} \frac{f\left(x_{i}\right)}{f^{\prime}\left(x_{i}\right)}
$$

Langkah-langkah untuk menentukan tingkat konvergensi menggunakan metode Newton Raphson sebagai berikut [11]:

1. Mencari nilai akar $r$ dari persamaan $f(x)$

2. Tentukan taksiran awal

3. Lakukan iterasi dengan $x_{i+1}=x_{i}-\frac{f\left(x_{i}\right)}{f \prime\left(x_{i}\right)}$

4. Mencari nilai error dengan menggunakan rumus:

$$
\varepsilon_{a}=\frac{\text { aproksimasi sekarang }- \text { aproksimasi sebelumnya }}{\text { aproksimasi sekarang }} 100
$$

5. Menentukan tingkat konvergensi $(\alpha)$ dengan rumus:

$$
\alpha \approx \frac{\log \left|\frac{x_{i+1}-x_{i}}{x_{i}-x_{i-1}}\right|}{\log \left|\frac{x_{i}-x_{i-1}}{x_{i-1}-x_{i-2}}\right|}
$$

\subsection{Metode Secant}

Metode secant merupakan metode iterasi yang mengatasi kelemahan metode Newton Raphson dengan mengaproksimasi $f^{\prime}\left(x_{i}\right)$ dengan garis secant. Metode ini memerlukan dua tebakan awal yaitu $x_{-1}$ dan $x_{0}[2]$.

Formulasi metode Secant yaitu

$$
x_{i+1}=x_{i}-\frac{f\left(x_{i}\right)\left(x_{i-1}-x_{i}\right)}{f\left(x_{i-1}\right)-f\left(x_{i}\right)}
$$

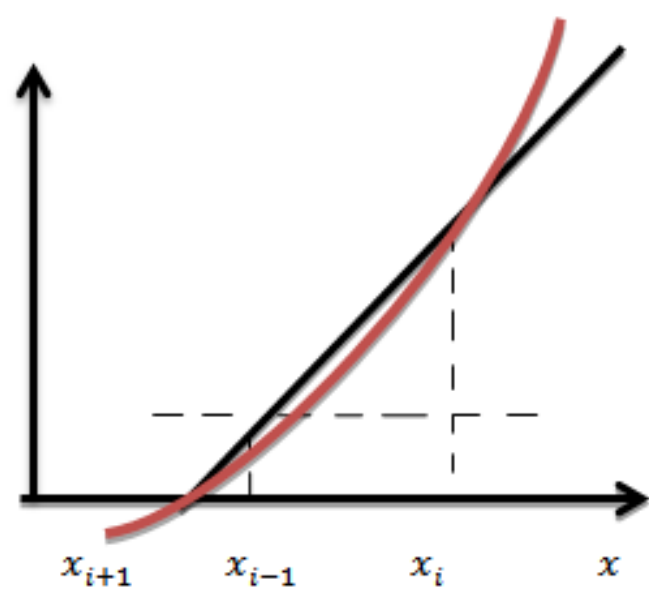

Gambar 2 Metode Secant [2]

Pada Gambar 2 taksiran akar diramalkan oleh ekstrapolasi sebuah garis singgung dari fungsi terhadap sumbu $x$. Metode secant lebih menggunakan diferensi daripada turunan untuk memakai kemiringan (slope) [2]. 
Langkah-langkah untuk menggunakan metode secant sebagai berikut:

1. Mencari nilai akar $r$ dari persamaan $f(x)$

2. Tentukan 2 taksiran awal

3. Lakukan iterasi dengan formula:

$$
x_{i+1}=x_{i}-\frac{f\left(x_{i}\right)\left(x_{i-1}-x_{i}\right)}{f\left(x_{i-1}\right)-f\left(x_{i}\right)}
$$

iterasi akan berhenti ketika $\left|\varepsilon_{a}\right|<\varepsilon_{s}$.

Adapun untuk mencari nilai tingkat konvergensi di dalam metode Secant sudah ditentukan yaitu dengan menggunakan persamaan $p^{2}-p-1=0$ mempunyai akar positif yang sederhana $p=\frac{1+\sqrt{5}}{2}=1.618 \ldots[3]$.

\subsection{Konvergensi dan Tingkat Konvergensi}

Definisi1. Misalkan $\left\{x_{i}\right\}$ adalah sebuah barisan yang konvergen terhadap $r$, dan $e_{i}=x_{i}-r$ untuk $i \geq 0$ jika terdapat bilangan konstanta galat $\lambda \neq 0$ dan tingkat konvergensi $\lambda>0$ [7], dengan

$$
\lim _{i \rightarrow \infty} \frac{\left|x_{i+1}-r\right|}{\left|x_{i}-r\right|^{p}}=\lim _{n \rightarrow \infty} \frac{\left|e_{i+1}\right|}{\left|e_{i}\right|^{p}}=\lambda
$$

Maka barisan $\left\{x_{i}\right\}$ konvergen terhadap $r$ dengan tingkat konvergensi $\alpha$ [5]. Jika $\alpha=2$ atau $\alpha=3$ maka metode hampiran memiliki tingkat konvergensi kuadratik atau kubik. Apabila dan $e_{i}=x_{i}-r$ merupakan kesalahan pada iterasi ke- $i$ pada suatu metode iterasi yang menghasilkan suatu barusan $\left\{x_{i}\right\}$, maka suatu persamaan

$$
e_{n+1}=c e_{n}^{p}+O e_{n}^{p+1}
$$

disebut sebagai persamaan galat pada iterasi ke-(n+1) dan c adalah koefisien tingkat galat ke$\alpha$.

Definisi 2. Andaikan $x_{0}, x_{1}, x_{2}, \ldots$ merupakan suatu barisan yang konvergen ke arah suatu bilangan $\xi$, dan tentukan $e_{n}=\xi-x_{n}$. Jika terdapat suatu bilangan $p$ dan suatu tetapan $\lambda \neq 0$ sedemikian rupa sehingga

$$
\lim _{n \rightarrow \infty} \frac{\left|e_{n+1}\right|}{\left|e_{n}\right|^{p}}=\lambda
$$

maka $p$ disebut tingkat konvergensi dari barisannya dan $\lambda$ disebut tetapan kesalahan asimtotik [3].

Misalkan $\lambda$ adalah akar dari $f(x)$ dan andaikan $x_{i+1}, x_{i}$ dan $x_{i-1}$ berturut-turut ialah iterasi yang dekat dengan $\lambda$ [7]. Maka perhitungan tingkat konvergensi $\alpha$ dapat diaproksimasikan dengan menggunakan rumus [7]:

$$
\alpha \approx \frac{\log \left|\frac{x_{i+1}}{x_{i}-x_{i-1}}\right|}{\log \left|\frac{x_{i}-x_{i-1}}{x_{i-1}-x_{i-2}}\right|}
$$

Dari tingkat konvergensi dan banyaknya evaluasi fungsi yang digunakan suatu metode iterasi dapat ditentukan nilai Efficiency Index, yang nantinya menunjukan tingkat effisiensi suatu metode iterasi dalam menghampiri akar persamaan non linier.

Definisi 3. Indeks Effisiensi didefinisikan sebagai $\alpha^{\frac{1}{m}}$, dimana $\alpha$ adalah tingkat konvergensi suatu metode dan m merupakan jumlah dari evaluasi fungsi yang diperlukan suatu metode tersebut. Semakin besarnilai indeksnya maka metode tersebut semakin efektif dalam menyelesaikan persamaan non linier [5]. 


\subsection{Metode Aitken's $\Delta^{2}$}

Metode Aitken's $\Delta^{2}$ digunakan untuk mempercepat konvergensi, metode yang dapat dipercepat konvergensinya dengan menggunakan Metode Aitken's $\Delta^{2}$ diantaranya yaitu metode Newton-Raphson dan metode Secant [1].

Asumsikan bahwa $p_{i}-p, p_{i+1}-p$, dan $p_{i+2}-p$ untuk $i$ yang cukup besar dapat dituliskan sebagai berikut [1]:

$$
\frac{p_{i+1}-p}{p_{i}-p} \approx \frac{p_{i+2}-p}{p_{i+1}-p}
$$

Kemudian

$$
\left(p_{i+1}-p\right)^{2} \approx\left(p_{i+2}-p\right)\left(p_{i}-p\right)
$$

Jadi

$$
p_{i+1}^{2}-2 p_{i+1} p+p^{2} \approx p_{i+2} p_{i}-\left(p_{i}+p_{i+2}\right) p+p^{2}
$$

dan

$$
\left(p_{i+2}+p_{i}-2 p_{i+1}\right) p \approx p_{i+2} p_{i}-p_{i+1}^{2}
$$

Kemudian formula untuk metode Aitken's $\Delta^{2}$ adalah:

$$
p \approx \frac{p_{i+2} p_{i}-p_{i+1}^{2}}{p_{i+2}-2 p_{i+1}+p_{i}}
$$

di mana $p_{i}$ adalah nilai aproksimasi dari hasil perhitungan sebelumnya (nilai aproksimasi dari metode Newton Raphson dan metode Secant).

Langkah-langkah menentukan tingkat kecepatan konvergensi dari metode Newton Raphson setelah mengaplikasikan metode Aitken's $\Delta^{2}$ adalah [6]:

1. Mencari nilai akar $r$ dari persamaan $f(x)$

2. Tentukan taksiran awal

3. Lakukan iterasi dengan $x_{i+1}=x_{i}-\frac{f\left(x_{i}\right)}{f\left(x_{i}\right)}$

4. Mencari nilai error dengan menggunakan rumus:

$$
\varepsilon_{a}=\frac{\text { aproksimasi sekarang }- \text { aproksimasi sebelumnya }}{\text { aproksimasi sekarang }} 100
$$

5. Menentukan tingkat konvergensi $(\alpha)$ dengan rumus:

$$
\alpha \approx \frac{\log \left|\frac{x_{i+1}-x_{i}}{x_{i}-x_{i-1}}\right|}{\log \left|\frac{x_{i}-x_{i-1}}{x_{i-1}-x_{i-2}}\right|}
$$

6. Menentukan tingkat kecepatan konvergensi dengan rumus:

$$
p \approx \frac{p_{i+2} p_{i}-p_{i+1}^{2}}{p_{i+2}-2 p_{i+1}+p_{i}}
$$

Langkah-langkah menentukan tingkat kecepatan konvergensi dari metode Secant setelah mengaplikasikan metode Aitken's $\Delta^{2}$ adalah[6]:

1. Mencari nilai akar $r$ dari persamaan $f(x)$

2. Tentukan 2 taksiran awal

3. Lakukan iterasi dengan formula:

$$
x_{i+1}=x_{i}-\frac{f\left(x_{i}\right)\left(x_{i-1}-x_{i}\right)}{f\left(x_{i-1}\right)-f\left(x_{i}\right)}
$$

iterasi akan berhenti ketika $\left|\varepsilon_{a}\right|<\varepsilon_{s}$. 
4. Menentukan tingkat kecepatan konvergensi dengan rumus:

$$
p \approx \frac{p_{i+2} p_{i}-p_{i+1}^{2}}{p_{i+2}-2 p_{i+1}+p_{i}}
$$

\subsection{Perbandingan Tingkat Kecepatan Konvergensi dari Metode Newton Raphson dan Metode Secant Setelah Mengaplikasikan Metode Aitken's $\Delta^{2}$}

Perbandingan Tingkat Kecepatan Konvergensi dari Metode Newton Raphson dan Metode Secant setelah mengaplikasikan Metode Aitken's $\Delta^{2}$ dari fungsi $f(x)=x^{3}-1$ terlihat pada Tabel 1.

Tabel 1 Perbandingan Tingkat Kecepatan Konvergensi dari Fungsi $f(x)=x^{3}-1$

\begin{tabular}{|c|c|c|c|c|}
\hline $\boldsymbol{i}$ & $\begin{array}{c}\text { Metode } \\
\text { Newton } \\
\text { Raphson }\end{array}$ & $\begin{array}{c}\text { Metode } \\
\text { Aitken's } \Delta^{\mathbf{2}} \\
\text { dari Metode } \\
\text { NR }\end{array}$ & Metode Secant & $\begin{array}{c}\text { Metode } \\
\text { Aitken's } \Delta^{2} \\
\text { dari Metode } \\
\text { Secant }\end{array}$ \\
\hline 0 & 2 & 0.77248 & 2 & 1 \\
\hline 1 & 1.4166 & 0.9622473 & 1 & \\
\hline 2 & 1.11054 & 0.998818 & 1 & \\
\hline 3 & 1.01064 & 1.004226 & & \\
\hline 4 & 1.00012 & 1 & & \\
\hline 5 & 1.00000003 & & & \\
\hline 6 & 1 & & & \\
\hline
\end{tabular}

Dari fungsi $f(x)=x^{3}-1$ dengan menggunakan metode Newton Raphson, pada saat iterasi ke- 6 diperoleh nilai yaitu 1 dan ketika mengaplikasikannya dengan metode Aitken's $\Delta^{2}$ tingkat kecepatan konvergensi dapat diperoleh dengan nilai yang sama yaitu 1 hanya pada iterasi ke-4. Sedangkan dengan menggunakan metode Secant pada iterasi ke-1 telah diperoleh yaitu 1.00000 sehingga tidak perlu mengaplikasikannya dengan metode Aitken's $\Delta^{2}$

Perbandingan Tingkat Kecepatan Konvergensi dari Metode Newton-Raphson dan Metode Secant setelah mengaplikasikan Metode Aitken's $\Delta^{2}$ dari fungsi $f(x)=x^{3}-1$ terlihat pada Tabel 2. 
Tabel 2 Perbandingan Tingkat Kecepatan Konvergensi dari Fungsi $f(x)=x^{3}-26$

\begin{tabular}{|c|c|c|c|c|}
\hline $\boldsymbol{i}$ & $\begin{array}{c}\text { Metode } \\
\text { Newton } \\
\text { Raphson }\end{array}$ & $\begin{array}{c}\text { Metode } \\
\text { Aitken's } \Delta^{2} \\
\text { dari Metode } \\
\text { NR }\end{array}$ & $\begin{array}{c}\text { Metode } \\
\text { Secant }\end{array}$ & $\begin{array}{c}\text { Metode } \\
\text { Aitken's } \Delta^{2} \\
\text { dari Metode } \\
\text { Secant }\end{array}$ \\
\hline 0 & 4 & 2.889178 & 3 & 2.994891 \\
\hline 1 & 3.20834 & 2.961014358 & 2.92308 & 2.962515 \\
\hline 2 & 2.98088 & 2.962489207 & 2.96199 & 2.9624809 \\
\hline 3 & 2.96261 & 2.96248 & 2.962502784 & 2.962501 \\
\hline 4 & 2.96249 & & 2.962490671 & \\
\hline 5 & 2.9624894 & & 2.962490799 & \\
\hline
\end{tabular}

Dari fungsi $f(x)=x^{3}-26$ dengan menggunakan metode Newton Raphson, pada saat iterasi ke5 diperoleh nilai yaitu 2.9624894 dan ketika mengaplikasikannya dengan metode Aitken's $\Delta^{2}$ tingkat kecepatan konvergensi dapat diperoleh dengan nilai 2.96248 pada iterasi ke-3. Sedangkan dengan menggunakan metode Secant telah diperoleh nilai yaitu 2.962490799 pada iterasi ke-5 dan ketika mengaplikasikannya dengan metode Aitken's $\Delta^{2}$ tingkat kecepatan konvergensi dapat diperoleh dengan nilai 2.962501 pada saat iterasi ke-3.

Dari Tabel 1 dan 2 untuk fungsi $f(x)=x^{3}-1$ terlihat bahwa yang paling cepat mendapatkan tingkat kecepatan konvergensinya yaitu dengan menggunakan metode secant. Sedangkan untuk fungsi $f(x)=x^{3}-26$ keduanya sama untuk mendapatkan tingkat kecepatan konvergensinya. Dilihat dari segi perhitungannya, menggunakan metode Aitken's $\Delta^{2}$ lebih cepat untuk mendapatkan nilai konvergensinya. Tetapi dilihat dari segi waktu komputasinya menggunakan metode Aitken's $\Delta^{2}$ lebih lama untuk mendapatkan nilai konvergensi.

\section{Simpulan}

Penentuan tingkat keceptan konvergensi dari metode Newton Raphson dan metode Secant menggunakan metode Aitken's $\Delta^{2}$ adalah dengan rumus umum sebagai berikut:

$$
p \approx \frac{p_{i+2} p_{i}-p_{n+1}^{2}}{p_{i+2}-2 p_{i+1}+p_{i}}
$$

Perbandingan tingkat kecepatan konvergensi dari metode Newton Raphson dan metode Secant berdasarkan contoh numerik dengan menggunakan metode Aitken's $\Delta^{2}$ yang paling cepat mendapatkan tingkat kecepatan konvergensinya untuk fungsi $f(x)=x^{3}-1$ adalah dengan menggunakan metode Secant. Sedangkan untuk fungsi $f(x)=x^{3}-26$ keduanya sama untuk mendapatkan tingkat kecepatan konvergensinya, baik dengan metode Newton Raphson maupun metode Secant.

\section{Daftar Pustaka}

[1]. Burden, R. L. dan Faires, J. D. 2001. Numerical Analysis $7^{\text {th }}$ Edition.USA: Brooks/ Cole

[2]. Chapra, S. C. 1991. Metode Numerik untuk Teknik, dengan Penerapan pada Komputer Pribadi. UI-Press, Jakarta.

[3]. Conte, S.D. 1980. Dasar-Dasar Analisis Neumerik. Edisi ketiga. Diterjemahkan oleh: Ir Mursaid, Jakarta: Erlangga.

[4]. Heath, T.M. 2002. An Introducting Survey. Departemen of Computer Science University of lllinois at Urbana-Champaign. 
[5]. Sahid. 2003. Analisis Dan Implementasi Metode Newton Raphson. Prosiding Seminar Nasional Hasil Penelitian MIPA dan Pendidikan MIPA UNY.

[6]. Smith, D.A dan Ford, W.F. 1982. Numerical Comparisions Of Nonlinier Convergence Accelerators. Mathematics Of Computation. Vol. 38, No. 158: 481-49

[7] Ranbir, S. dkk. 2013. On The Rate of Convergence of Newton Raphson Method. The International Journal Of Engineering And Science (IJES). 